\title{
Los tropos como figuraciones de los saberes: una forma de contribuir al pensamiento decolonial
}

\author{
Tropes as knowledge figures: a contribution to decolonial thinking
}

Sylvia Contreras Salinas (sylvia.contreras.s@usach.cl) Departamento de Educación, Universidad de Santiago de Chile (Santiago, Chile) http://orcid.org/0000-0003-2297-2399

Paloma Miranda Arredondo (paloma.miranda@usach.cl) Departamento de Educación, Universidad de Santiago de Chile (Santiago, Chile) http://orcid.org/0000-0003-3122-7745

Mónica Ramírez Pavelic (trapecio@gmail.com) Departamento de Ciencias de la Salud, Universidad Arturo Prat (Iquique, Chile) http://orcid.org/0000-0003-2710-2982

\begin{abstract}
This article proposes to configure knowledge-trope plot as a strategy to uncover colonial ties that persist in the daily lives of situated and incarnated subjects, whose existences develop in conditions of material precariousness, exclusion, exploitation and non-recognition. With a marked epistemic-methodological character, and based on the postulates of the tropology, the notion of trope and knowledge is discussed, as well as pointing out the possible relationships that can occur between them, and finally, in demonstrative terms, to propose a procedure aimed at identifying and analysing the tropes that allow us to reveal colonial ballasts in everyday narratives. The relevance of this proposal is based on the need to construct methodological tools that allow us to understand the principles of decolonial thinking. From there, the trope is proposed as an expression and figurative discussion of knowledge, because it can be used persuasively to affect the way in which the world is inhabited, while at the same time it allows us to understand social action and, consequently, colonial matrices with which we must break.
\end{abstract}

Key words: knowledge, colonial veils, tropology, methodology, daily life.

\section{Resumen}

Este artículo se propone configurar la trama saber-tropo como estrategia para desvelar ataduras coloniales que aún persisten en las vidas cotidianas de sujetos situados y encarnados, cuyas existencias se desarrollan en condiciones de precariedad material, exclusión, explotación y no reconocimiento. Con un marcado carácter epistémico-metodológico, y tomando como base los postulados de la tropología, se discute sobre la noción de tropo y saber, además de señalar las posibles relaciones que entre ellos se pueden dar, para finalmente, en términos demostrativos, plantear un procedimiento orientado a identificar y analizar los tropos que permiten ir desvelando lastres coloniales en las narraciones cotidianas. La relevancia de esta propuesta se asienta en la necesidad de ir avanzado en construir herramientas metodológicas que permitan comprender los principios que configuran el pensamiento decolonial. Desde allí, se propone al 
tropo como expresión y discusión figurativa del saber, debido a que este puede ser utilizado persuasivamente para afectar la forma en que se habita el mundo, al tiempo que permite comprender el accionar social y, consecuentemente, las matrices coloniales con las que debemos romper.

Palabras clave: saberes, velos coloniales, tropología, metodología, vida cotidiana.

\section{Introducción}

Atendiendo a nuestra condición de investigadoras, habitantes de Latinoamérica, nos moviliza la necesidad de aportar en la construcción de un pensamiento crítico latinoamericano, particularmente desde la perspectiva decolonial. En esta línea, asumimos, humildemente, el compromiso de proponer abordajes investigativos que releven lo imprescindible de atender a la vida cotidiana, específicamente, en los saberes que se generan y circulan en este ámbito, configurándose en y desde el lenguaje. A partir de aquí, Ortiz (Decolonizar la investigación en educación) plantea la existencia de saberes en que las palabras nombran lo que se sabe y lo que se ignora, conformando la objetividad de nuestra subjetividad, génesis de las configuraciones lingüísticas interhumanas. Por nuestra parte, intentamos contribuir a una investigación que no solo se aplique a la cotidianidad, sino también al pensamiento que es parte de ella; afirmando que la cotidianidad sería lo único que vale la pena ser pensado, en y desde sus lenguajes.

Así, Saladino (El latinoamericanismo como pensamiento descolonizador) plantea que es posible repensar el mundo y transformarlo desde las propias experiencias de los sujetos del sur, mientras que para Lander (Ecología política latinoamericana), lo principal es reforzar una mirada epistemológica que critique el carácter eurocéntrico del pensamiento hegemónico que impera en la actividad investigativa de las ciencias sociales. Considerando, tal como argumentan Mignolo (Habitar la frontera) y Grosfoguel y Almanza (Lugares decoloniales), que el poder colonial persiste localmente y cotidianamente, podemos sostener que estamos frente a una dominación territorial directa, donde las clásicas formas de control y vigilancia fueron abandonadas por una performance que permite más libertades, y amplía el campo de consumo material y simbólico, pero, que igualmente sigue fundamentada en la organización social jerárquica y asimétrica. Lo anteriormente descrito hace evidente la necesidad de una práctica decolonial que permita desatar-nos de las relaciones de poder colonial, identificando para ello las ataduras en las microactividades y micro-lenguajes que habitamos. Por esto, se exhorta a una producción investigativa que proponga formas de desvelar lo colonial que persiste en las experiencias cotidianas, constituyendo registros impuestos que nos interpelan para formular estrategias colectivas de resistencia.

Considerando las ideas expuestas, este artículo se propone configurar la trama saber-tropo como estrategia para desvelar ataduras coloniales que aún persisten en las vidas cotidianas de sujetos situados y encarnados, cuyas existencias se desarrollan en condiciones de precariedad material, exclusión, explotación y no reconocimiento. Esta propuesta, plantea un propósito epistémico-metodológico, exponiendo, además, en términos demostrativos, un procedimiento para identificar y analizar los tropos que en las narraciones asumen un carácter de pivote, toda vez que permiten ir desvelando los lastres coloniales que de modo sutil aparecen en la cotidianeidad.

En consonancia, este trabajo desarrolla tres puntos principales: el primero, intenta dar cuenta de la concepción de tropos y saberes, ahondando en su relación, para luego, como segundo punto reflexionar y profundizar en lo que hemos denominado saberes oscuros. En el último punto, se analiza la propuesta de la tropología como posibilidad de fuga de las ataduras coloniales, a través de hallazgos de 
investigaciones de corte etnográficas que permiten proyectar el trabajo con los tropos desde esta perspectiva. La relevancia de esta propuesta se asienta en la necesidad de ir avanzado en construir herramientas metodológicas que permitan analizar los principios que configura el pensamiento decolonial. Desde allí, se propone al tropo como discusión y expresión figurativa del saber, pudiendo ser utilizado persuasivamente para afectar la forma en que se habita el mundo, permitiendo de paso, comprender las acciones sociales y consecuentemente, las posibles matrices coloniales con las que debemos romper.

\section{La configuración tropo-saber}

Desde nuestras experiencias investigativas, rescatamos lo que para muchos es una utilización inadecuada del lenguaje, pero que, no obstante, forma parte esencial del mismo. En este sentido, relevamos la figura de los tropos, señalando que este recurso no puede ser entendido como un mero factor de distorsión o una anomalía semántica que amenaza el orden del discurso literal. Por el contrario, Innerarity (El saber de las metáforas) lo plantea como un factor de reflexión en el que el orden del lenguaje se refleja y recategoriza. Por tanto, se les denomina tropos porque al utilizar una palabra en sentido figurado, la adornamos para hacerla significar lo que de modo alguno significaría originalmente. Desde esta perspectiva, se pueden convertir en el núcleo de configuraciones lingüísticas interhumanas que hacen justicia a la contingencia de sus categorías, conformando un medio insustituible para la captación de contextos y relaciones.

Los tropos como figuraciones apuntan a algo fuera de sí. Tienen intencionalidad, además de sentido literal o analógico, constituyendo su opacidad un rasgo distintivo. El tropo como terminología técnica en la disciplina de la retórica, considera "el uso de una palabra o expresión, en un sentido diferente del que le pertenece correctamente, en orden de otorgar vivacidad, énfasis, perspectiva, coloración, a una idea" (Perelman y Olbrechts 2009:56). Entre las principales clases de tropos encontramos la ironía, la metonimia, la metáfora y la sinécdoque, variedades que han sido profusamente identificadas en los distintos tratados sobre retórica existentes.

Al dar cuenta de un giro en la construcción de ciertos anunciados, los tropos anuncian un modo de entender el lenguaje como una forma de acción del ser humano, por medio de los símbolos utilizados para responder frente a situaciones particulares. Debido a esto, podemos decir que ellos poseen el carácter pragmático del lenguaje. Asimismo, conllevan el reconocimiento de las similitudes y diferencias de los significados en las relaciones entre elementos, las cuales pueden ser de comparación, de contigüidad, de causa efecto, de acentuación, entre otras. Este rasgo es lo que nos permite identificar la existencia de ataduras coloniales, puesto que, como figuraciones se ubican en el "ámbito de las configuraciones o transfiguraciones del mundo". En otras palabras, ordenan y estructuran las experiencias, "aquello que se retiene cognitivamente", además de conformar patrones "conceptuales que no son solo formas a partir de las cuales se concibe un mundo ya clasificado, sino, sobre todo, formas que contribuyen a constituir ese mundo" (Ibáñez 2014:145).

En este contexto, los tropos nombrarían lo conocido asociado a lo desconocido, transgrediendo la lógica conceptual y lexical en el lenguaje, además de inducir un rodeo orientado hacia aquello que no puede nombrarse a través de la expresión directa. Dichas cualidades fueron el foco de los estudios antropológicos en la época de los sesenta, particularmente, aquellos aspectos relacionados con los efectos sociales. Según Fernández (La tropología y la figuración del pensamiento y de la acción social), todo esto da origen a la perspectiva tropológica. 
Lo anterior, daría cuenta de un giro que pone de manifiesto el espesor propio de los discursos en la retórica, permitiendo un estudio post convencional, además de favorecer la resistencia a la práctica de desechar los lenguajes cotidianos, por carecer estos de una supuesta rigurosidad al estar alejados de sus usos literales, los cuales son impuestos por las instituciones que definen qué lenguajes son legítimos. Considerando estas propiedades, nos atrevemos a plantear una relación yuxtapuesta entre tropos y saberes, especialmente si retomamos el pensamiento de Rodolfo Kusch, respecto a los saberes, los cuales se construyen "de términos multívocos y de conceptos indicativos multidimensionales. Así pues, la metáfora, la personificación, el modo subjuntivo, y el uso simbólico del lenguaje, son los elementos con los que se construye el saber local, como un instrumento de comunicación de doble pista: empírico y simbólico, a la par" (Kusch 1973:260).

\section{Los saberes: subversión del sujeto}

Situarse en una perspectiva decolonial implica mirar con atención los conceptos que se utilizan, en tanto, el uso irreflexivo del lenguaje conlleva el riesgo, en ocasiones, de esgrimir palabras que a pesar de resultar útiles para el autoentendimiento (ya que todos las manejan) naturalizan prácticas subordinadoras, en tanto nadie las explica. Tal oscuridad parece ser una motivación extra para utilizarlas frecuentemente, pues permite extremar la extensión de su uso, aun cuando, diciendo algo no se diga nada. Por esto, los saberes pertenecen, sin lugar a duda, a ese tipo de conceptos que manejamos sin dificultad, pero que, sin embargo, no podemos explicar con facilidad cuando se nos pregunta qué son.

Esto, debido a que ellos se han convertido en un importante concepto que abrevia una extensa multiplicidad de fenómenos ampliamente conocidos, especialmente en el contexto latinoamericano. Así también, los saberes refieren a un tipo de concepción recurrente en las propuestas teóricas decoloniales o poscoloniales, que ha permitido una amplia reflexión crítica de parte de organizaciones, movimientos sociales y del mundo académico, la cual se ha venido desarrollando respecto de la producción del conocimiento. En este abordaje, prima la idea que, para la recuperación del poder se debe re-establecer el estatus de los saberes, aquel del que según Boaventura de Sousa Santos (Epistemologías del sur) un importante número de comunidades fueron despojadas o imposibilitadas de generar.

Asimismo, según Contreras y Ramírez (Análisis fenomenológico del tropo "pasar a llevar") es posible apreciar cómo en los distintos apelativos de los saberes prevalece su vinculación con la cotidianeidad, es decir, con los haceres/saberes de seres humanos situados y encarnados, a partir de cuya diversidad su polisémica categoría queda en evidencia. Esto se traduce en una multiplicidad de nombres: Saberes locales para Kusch (El pensamiento indígena y popular en América) y Leff (Aventuras de la epistemología ambiental: de la articulación de ciencias al diálogo de saberes); Sabiduría popular para Martinic (Saber popular e identidad. Educação popular: utopia latino-americana); Conocimiento campesino para Toledo (Ecología, campesinado e historia) y Nuñez (Los saberes campesinos: implicaciones para una educación rural); Saberes cotidianos para Heller (Sociología de la vida cotidiana); Saberes menores o sometidos para Foucault (Defender la sociedad. Curso en el College de France (1975-1976); Sistemas de saberes indígenas y campesinos para Schmelkes (El conocimiento campesino); Epistemologías locales para Descola y Pálsson (Naturaleza y sociedad); Saberes colectivos para Argueta (El diálogo de saberes, una utopía realista); Conocimiento popular y ciencia del pueblo para Fals Borda (Conocimiento y poder popular); Saberes otros para Grosfoguel (Sujetos coloniales: una perspectiva global de las migraciones caribeñas), Grosfoguel y Almanza (Lugares decoloniales) y Grosfoguel y Mignolo (Intervenciones decoloniales: una breve 
introducción); Saberes ancentrales para Cortez (Régimen de saber ancestral) y Quijano (América Latina: hacia un nuevo sentido histórico).

En consonancia y siguiendo a Contreras y Ramírez, es posible visualizar en estas denominaciones la conformación del poder-saber que se revela en los esfuerzos por caracterizarlos a partir de sus formas de reproducción, estructuración, transmisión o distribución. Conjuntamente, para Boaventura de Sousa Santos (Descolonizar el saber, reinventar el poder; Para descolonizar occidente), las investigaciones cuyo centro son los saberes -en sus distintas denominaciones- se han revitalizado con sus respectivas actuaciones en la creciente prominencia de movimientos sociales situados en zonas geográficas poco valoradas, y al margen de las jerarquías socioeconómicas. Esto es confirmado cuando en muchos casos se declara que los saberes de los pueblos indígenas, campesinos y afrodescendientes, son un aspecto ineludible cuando se desea avanzar en sociedades sustentables y justas.

Sin la pretensión de querer zanjar el carácter polisémico del concepto, parece indesmentible la necesidad de ahondar en su esclarecimiento, en especial, cuando se requiere instalar un nuevo lenguaje que aporte a esclarecer los complejos procesos emplazados en la dicotomía modernidad/colonialidad. En efecto, aclarar conceptos, es y ha sido, una de las tareas más características de la investigación que se encuentra en permanente vigilancia epistemológica. Sin embargo, no se trata de la aclaración desde un trabajo contemplativo, sino en y desde la experiencia investigativa, y desde la vivencia de pertenecer a una comunidad subalternizada.

No podemos olvidar que según Heller (Sociología de la vida cotidiana) los saberes se constituyen en la vida cotidiana, que ontológicamente representa el lugar de reproducción de la individualidad social, lo que crea, a su vez, la posibilidad de reproducción social. Esto constituye, según De Certeau (La invención de lo cotidiano II. Habitar) un campo cultural donde la gente común se expresa contra el orden dominante, mediante sus propias formas.

A partir de aquí, surge una cotidianidad que para Giglia (El hábitat y la cultura: perspectivas teóricas y de investigación) se da en el habitar, conformándose según Melich (La prosa de la vida) en un ser-sí mismo, pero también en ser-tú y ser-en-el-mundo, lo que implica habitar-se. De este modo, el saber es lo que emerge y se recrea según los intereses pragmáticos y la situación general que cada sujeto vive dentro de una sociedad determinada, conformándose según Berger y Luckmann (La construcción social de la realidad) en la más relevante estructura básica que concierne a la vida cotidiana.

En consecuencia, Contreras, Bambague y Barrera (Saberes que configuran trayectorias migratorias: narraciones de mujeres colombianas migrantes en Chile) proponen concebir los saberes como la capacidad que tiene el sujeto de habitar-se en el mundo, anunciando su necesidad de ser sujeto en un complejo conjunto de puntos de referencia, mismos que le permiten determinar dónde está y en cuál está siendo. Esta testimonialidad de la existencia se constituye en una multiplicidad de formas de habitar-se en el mundo y es asunto de cada sujeto. En este sentido, los saberes tienen relación con la subjetividad, estableciendo procesos que integran la sujeción y la des-sujeción.

La universalidad de la concepción que sugerimos es el punto de partida de nuestra propuesta, al dejar de manifiesto el anhelo de desestabilizar la esfera del conocimiento universal, apostando por la especificidad del propio lugar. Desde allí, corresponde interrogarnos acerca de los saberes que necesitamos relevar para 
contribuir a procesos corrosivos de las matrices coloniales, a la par de cómo dar cuenta de ellos, de manera que no sean encapsulados para su posterior regulación.

\section{Los saberes oscuros}

La especificidad de cada lugar o los múltiples habitar-se, nos desafían a preguntarnos si los saberes deben ser pensados siempre en positivo; en un contexto en que se ha afirmado, frecuentemente, que ellos sostienen estrategias locales, además de contra-estrategias frente a las iniciativas impulsadas por intereses económicos trasnacionales, ya sean legales o ilegales. De este modo, los saberes sustentan prácticas de resistencia con alta carga política que impulsan movimientos sociales. No obstante, reconociendo, al igual que Heller que los saberes son el producto de estructuras, relaciones e interacciones de la vida cotidiana en una determinada época, es inevitable sospechar, en especial si no se ahonda en ellos para reconocer qué aspectos ocultan, permitiendo que se mantengan ciertas lógicas y estructuras, puesto que al igual que el racismo, lo colonial no sale sin maquillarse.

Por lo tanto, existe la posibilidad de no identificar sus enmascaramientos debido a coherencias prácticas o sistematizaciones formales, permaneciendo el riesgo de no lograr "reencontrar la eclosión de los enfrentamientos y las luchas que los arreglos funcionales o las organizaciones se han propuesto enmascarar" (Foucault 2001:21).

Entonces, conociendo la multiplicidad de saberes y el hecho que habitamos matrices coloniales, es necesario desvelar los lastres de aquellos saberes que nos constituyen. Esto requiere según Hale y Stephen (Otros saberes) desvelar el cruce y mixtura de las comunidades, así como el conflicto y resistencia generada frente a la estigmatización, la racialización y la negación a la que se han visto expuestos. Comprendiendo que muchos de estos saberes se gestaron en formas violentas, tejiendo canales de oposición que no necesariamente tienen una significación radical, ni es una respuesta definida a la dominación. Es por esto que según Giroux y McLaren (Sociedad, cultura y educación) en algunos de ellos se expresa la represión que ha sido inscrita por parte de la cultura dominante.

Nos referimos a saberes que siguen sigilosamente guardados en la memoria colectiva de las comunidades, las que a través de sus prácticas y enseñanzas reproducen la acción articulada de la dominación. A partir de aquí, Arduino (Mujeres y feminismo en África poscolonial) señala que por su carácter, estos saberes permiten rescatar la lucha emocional y sentida de habitar en formas complejas, hospedando a la vez al enemigo y a nosotros mismos. Describimos saberes oscuros, que según Zipin (Dark funds of knowledge, deep funds of pedagogy) culminan en experiencias violentas, pero que, no obstante, son elocuentes frente a la necesidad de sobrevivir, siendo gestados, además, según Contreras y Ramírez en escenarios adversos.

En este marco, una perspectiva decolonial implica según Du Bois (Las almas del pueblo negro) quitar los velos coloniales, de manera de reconocer la especificidad de la opresión, permitiendo según Kristeva (Sentido y sinsentido de la rebeldía) plantearse la pregunta por la resistencia, al definir quién debe rebelarse y contra qué. En el entendido que, según Lugones (Colonialidad y género y Hacia metodologías de la decolonialidad), una matriz colonial activa prácticas, maneras de ser y de pensar, que para cada cual son constitutivas, oponiéndose a una reducción deshumanizante, frente a lo que se está forzando y a la resistencia a ser sujetos permitidos. De esta forma y siguiendo a Alabarces (Posludio: Música popular, identidad, resistencia y tanto ruido (para tan poca furia), los saberes oscuros posibilitan reconocer algunos estados de dominación específicos vinculados a situaciones particulares. Esto es especialmente válido, 
según Aman (Why interculturalidad is not interculturality) cuando adscribimos a la idea que la liberación del colonialismo exige que la interculturalidad sea reclasificada como inter-epistémica, para que, desde una perspectiva decolonial se centre en cómo se crean y mantienen las diferencias sobre las identidades culturales.

\section{La tropología: una [posibilidad de] fuga para descentrar el pensamiento colonial hegemónico}

Recapitulando lo plateado, consideramos central al igual que Mignolo (Habitar la frontera) el reconocimiento que la cotidianidad como experiencia común se transfiere en un grado decisivo en el lenguaje. Comunicación que, al ser verbal, deja pistas que pueden ser rastreadas en el tiempo y el espacio, en tanto, sobredetermina importantes aspectos que incluyen desde la economía hasta la realidad social. Por ello, reiteramos que los saberes no pueden separarse de los lenguajes, pues este es el punto de partida, debido a que el lenguaje no constituye solo una cualidad que los seres humanos tienen, sino algo que son. De ahí que la colonialidad del lenguaje es también la colonialidad del ser.

A partir de aquí, la tropología se constituye en una posibilidad, precisamente porque se fija en las cualidades de los tropos como oportunidad de entender qué hay detrás u oculto en estos giros del lenguaje, en el marco de admitir que "cuando nos enfrentamos a una situación difícil, la mente da la vuelta y piensa sobre alguna otra cosa que, de forma similar, pero en algunos aspectos, no en todos, pueda ofrecer una perspectiva que logre animar o esclarecer ese tema" (Fernández 2006:24).

Trabajar desde la tropología nos obliga a adoptar una perspectiva que acoja como tesis central que el hecho de quitar los velos coloniales ha de ser concebido como un ocuparse de crear, trasmitir y descifrar las figuraciones del saber que se anuncian en los tropos. Es decir, transitar por los intersticios "que se mueven entre dos fenómenos: por una parte, la información que alude a una señal cuajada (huellapalabra) y por otra, la formación que invita a re-conocer las señales que están ahí (escudriñar la ideahuella), suscitando un movimiento liminal entre la inscripción y la descripción e interpretación de la señal" (Restrepo 2007:108). En este contexto, Ricoeur plantea en su libro Hermenéutica y acción, que los tropos derivan de una teoría extralingüística o ideológica, lo que, en palabras de Hart (Critical discourse analysis and metaphor) desafía a la perspectiva decolonial a contar entre sus focos con un análisis micro, a nivel de ejemplos concretos de discursos en la cotidianidad, particularmente, de la forma en que estos se representan en el ámbito político y social.

En suma, la tropología conforma un campo donde es posible llevar a cabo la tarea de descorrer los velos coloniales de los lenguajes que habitamos y nos habitan, facilitando procesos de apertura y de constante interrogación desde las propias localizaciones. Lo anterior podría incluso dar paso a la desobediencia, lo que permitiría robustecer un lenguaje decolonial. Sin embargo y, por sobre todo, los tropos expresan lo que se desea dejar lejos de los ojos del poder dominante, una contraseña o la potencialidad de anunciar micropolíticas de resistencias que sitúan al lenguaje como gestor de posibilidades.

En esta línea, argumentamos que el análisis tropológico involucra poner en movimiento una doble relación entre los modos de distanciarse del absolutismo que refleja la realidad. Por una parte, la conciencia del giro que lo conforma; lo cual lleva a reconocer a la memoria como mediadora de la comprensión; y por otra, la libre variación de la historia personal. De esta manera, se iluminan zonas vinculadas al habitar-se que hasta entonces se encontraban alicaídas, pues al entrar en juego los tropos ganarían en protagonismo, 
elevándose a lo que Blumenberg (Paradigmas para una metaforología) considera un nivel de apropiación superior, colmándolo de posibles.

Frente a esto, la tropología permite aumentar la resonancia "de la lengua a la que pertenece y deja aparecer el conjunto de la acepción de mundo que le subyace" (Gadamer 2017:194) a cada ser humano. Ofreciéndonos una polifonía que tributa a los intentos de exponer la relación entre el orden del discurso y el aspecto colonial del ser-saber, insistiendo según Anzaldua (La frontera) en la propuesta de atender a los tropos como un "marco" donde deben ser interpretadas y re-significas las heridas coloniales, las que según Lara (Pensamiento decolonial como instrumento transgresor de la globalización) entregan un objeto de estudio denso, con el fin de establecer una política metodológica decolonial, que rompa la monoglosia y distinga las voces, incluso entre aquellas que habitan en el propio sujeto, permitiéndonos discernir cuándo la voz que se escucha es suya y no de otro.

\section{Cómo desvelar saberes de sujetos subalternizados en y desde la tropología}

Una metodología que aporte a desvelar discurso y practicas coloniales debe, en primer lugar, concebir la investigación como la oportunidad de subjetivarnos desde otros lugares y lenguajes. Reconociendo que lo colonial está constituido por voces impuestas, represiones, negaciones y huellas de violencia en el plano de lo invisible e inaudible. Según Haber "la violencia que crea el mundo colonial produce relaciones evestigiales que luego niega" (2011:17), añadiendo que a todo vestigio le sucede la ruptura que lo transforma en presencia y ausencia. De ahí que una propuesta metodológica debe ser capaz de cartografiar estas violencias, convocando a los dichos-no dichos en conversaciones con el mundo interno y externo.

Desde nuestro punto de vista, uno de los lineamientos que permite la emergencia de esta cartografía es la narración. Por ello, se insta a abordar esta perspectiva, concibiéndola como una acción investigativa que deriva de una determinada comprensión de la realidad, la cual según Grollmus y Tarrés (Stories about methodology) ofrece entre otras cosas, la posibilidad de crítica a los discursos hegemónicos, en la medida que estos entreguen experiencias corporeizadas en formas específicas de subjetividad. Con todo, según Ricoeur las narraciones aportan a la co-existencia de dos dimensiones: la dimensión episódica que da cuenta de los acontecimientos y la configurativa que significa y resignifica a partir de hechos diseminados. En estas dimensiones de la narración es posible un abordaje en y desde los tropos, ya que en la construcción de narrativas es posible significar algunos acontecimientos.

Por tanto, esta metodología debe, desde la dimensión configurativa de la narración, ofrecer procedimientos que como ya hemos señalado, permitan retirar los velos coloniales. Para ello, se propone un procedimiento de análisis que considera los siguientes pasos:

1) Predicaciones tropológicas. Consiste en reconocer aquellas declaraciones en que existen relaciones lógicas de clasificación y contraste, donde es preciso apelar a un dominio cognitivo diferente al que normalmente se asocia. Nos referimos a expresiones a las que recurren los interlocutores cuando comparten lo que les sucede, haciendo uso de su capacidad de persuadir o sugerir. llustrativamente: "Chelo: depende de lo que quiere ser en la vida, de lo que quiere tener. Si uno no es alguien, debe trabajar, pero si quiere seguir siendo así, se va a conformar con lo que tiene. Pero si quiere salir adelante, lo hace con los medios de uno, con la fuerza de uno" (Contreras 2013:245). 
En esta cita destacan tres expresiones o tropos que median entre la dimensión social y la subjetividad, conformándose en tropos-saber, además de permitir establecer las jerarquías y valores que actúan, así como justificar las elecciones, sin olvidar que su invocación resulta imprescindible para que el relato sea eficaz.

2) Análisis de los tropos como figuraciones del saber. Este análisis se realiza en términos de cómo se estructura el concepto, mediante la semejanza con otro término similar; comprendiendo que el tropo es una especie de meta-afirmación de los términos fuente y campo de la relación trópica, el que además es capaz de señalar "cómo el campo debe ser interpretado" (Turner 2008:31). A modo de ejemplo, en el marco del siguiente relato el tropo salir adelante da cuenta de cómo debe ser interpretado:

"Don Juan: Yo encuentro que si yo llegué aquí, que el hijo o el nieto sea más allá, que llegue más arriba, que no llegue donde llegue yo, yo creo que puede ser así.

Ana: Que este más arriba.

Don Juan: O sea, que sea más, un poco más que mí, que salga adelante.

Entrevistadora: ¿Le preocupa que al llegar más arriba se olvide de ustedes?

Don Juan: En algunos casos sucede eso, que ya por estar más alto, ya no lo miran ya, eso está sucediendo. Ana: Pero aquí hay un caso, que Juanjito tiene sus estudios y Juanjito nunca ha mirado en menos a nadie. Don Juan: Ah! Juanjito nunca ha cambiado, sigue siendo igual.

Ana: Hasta aquí Juanjito ha sido igual" (Contreras 2013:251).

A partir de este relato se debe implementar un dispositivo que permita reconstruir los posibles sentidos y significados del tropo, procurando no reducirlos a comparaciones literales. Asimismo, según Beuchot (Hermenéutica analógica y símbolo) se admite su descomposición, apelando a la fuente o características concretas que los acotan, sin llegar a agotarlos. Para esto se hace necesario dar cuenta de la relación entre fuente y tema, poniendo en relieve los significados de ambos, como producto de la interacción entre los dos polos o marcos, considerando los tropos como figuración del saber.

Siguiendo a Assens y Alcolea (Tropos), necesitaríamos una descripción detallada de cada componente del tropo, para lo cual podemos ayudarnos por una lista de palabras o expresiones claves, con especificaciones acerca de su interconexión y significados paradigmáticos en el ámbito del que fueron originalmente extraídas. A modo de ejemplo, la tabla 1 presenta una propuesta de relación fuente-tema del tropo salir adelante.

Tabla 1

Fuente: SALIR ADELANTE = Tema-saber: LA EXISTENCIA ES SALIR

\begin{tabular}{|l|l|}
\hline $\begin{array}{l}\text { Propiedades proyectadas de } \\
\text { salir }\end{array}$ & $\begin{array}{l}\text { Pasar de adentro hacia afuera; Desencajarse; Librarse de un lugar } \\
\text { o situación; Aparecer; Manifestarse; Estar de una manera } \\
\text { determinada; Empezar a existir; Dejarse ver; Nacer } \\
\text { Apartarse, separarse; Ocurrir; Resultar; Venir a ser; Llegar a feliz } \\
\text { término en algo; Hacer su voluntad; Surgir; Mejorar. }\end{array}$ \\
\hline $\begin{array}{l}\text { Propiedades proyectadas de } \\
\text { adelante }\end{array}$ & $\begin{array}{l}\text { Movimiento; En tiempo futuro; Hacer o seguir haciendo algo } \\
\text { Paso a un lugar; Prosperar; Hacer progresos; Tener un buen fin; } \\
\text { Triunfar; Superar situaciones adversas; Llegar a tener; Avanzar; } \\
\text { Acercarse a su fin. }\end{array}$ \\
\hline
\end{tabular}


Figuraciones del saber respecto a la existencia:
Librarse de un lugar para pasar a otro; Dejarse ver para hacer progresos; Venir a ser, superando situaciones adversas; Empezar a existir al acercarse a su fin; Llegar a tener, haciendo su voluntad; Aparecer en la acción de pasar a otro lugar; Mejorar para desencajarse de una condición; Dejarse ver por tener un buen fin.

Fuente: Extraída de Contreras (Esbozando una pedagogía vulnerable. Narrativas y retoricas locales).

Esta tabla expone el ejercicio de dar cuenta hacia donde podríamos orientar el análisis del tropo, haciendo referencia a un sentido que esta fuera de sí, y que solo al descubrir el significado de los elementos que lo componen, se podría acceder al saber relacionado con la existencia. Por tanto, se intenta desvelar el lazo que une el sentido literal con el simbólico, en el entendido que las propiedades proyectadas de los términos que componen el tropo le otorgan un énfasis particular que solo en la trama de cada relato se puede reconocer. Con esto, dicho relato adquiere, a su vez, un sentido en el marco sociocultural e histórico en que se construye, quedando claro que se requiere realizar un mapeo permanente y selectivo entre dominios, pues cada una de las propiedades alumbran algunos aspectos de la experiencia y esconden otros. Lo importante es poner en movimiento el principio de relevancia, es decir, el re-conocimiento del contexto para definir las proyecciones más verosímiles.

3) Alertar la dinámica entre los tropos y las consecuencias sociales. Considerando que los tropos anuncian situaciones sociales particulares en culturas también particulares, según Ibáñez (Por una sociología de la vida cotidiana) se debe proceder con cautela en la actividad hermenéutica, con el fin de asegurar su anclaje en el trabajo de campo y en el marco socio-cultural e histórico, así como en la situación social especifica de investigación.

llustramos esta idea mediante la interpretación del tropo venido a menos: "Cuando un patrón le dice a su inquilino "eres un venido a menos", se está formulando un enunciado mediante el cual se expone la disociación entre devenires "ser más" y devenires "ser menos"; existencias dominadoras/valoradas versus existencias subordinadas/desvaloradas. Al enunciar esta idea, el patrón ejecuta la acción de dominación mediante la cual reclama ser definido como "un venido a más", construyendo una relación de desigualdad en la dimensión ilocutiva. Al mismo tiempo, el uso de una u otra locución permite al receptor hacerse una idea de quién pronuncia determinada frase -como en el ejemplo eres un venido a menos- pasando a un lugar secundario la información referencial del enunciado. Por otra parte, en su dimensión perlocutiva, persuade, seduce, intimida o convence. En el ejemplo formulado, el objetivo parece ser convencer al inquilino que no tiene derecho a ciertas pretensiones, porque su esencia es menos, no existiendo en él la potencia de ser más, es decir, promovería un devenir devaluado que se produce al decir lo que se dice" (Contreras 2013:187).

4) Reconocer los juegos de tropos. No es suficiente el análisis aislado de los tropos, aunque creamos reconocer un saber en el momento de su expresión, atendiendo a un fenómeno en particular. En este sentido, no podemos olvidar lo que Fernández (La tropología y la figuración del pensamiento y de la acción social) señala como una importante regla de los tropos y es que estos interactúan entre sí y pueden transformarse unos en otros, por lo tanto, es necesario reconocer estos juegos. Siguiendo con el ejemplo del tropo salir adelante, este por sí solo no logra dar cuenta de los saberes gestados y recreados en el modo de habitar-se en relación con las preocupaciones existenciales, requiriendo que se atienda a otros tropos, por ejemplo: "que no te pasen a llevar", "agrandarse para no ser menos", "hay que ser otro", 
"estudiar para mandar al más chico", "llegar a ser alguien", "que sea más que yo", "se han criado regalaos" (Contreras 2013:136).

Estos juegos de tropos se encuentran anclados, al decir de historiadores como Salazar (Mercaderes, empresarios y capitalistas) y Bengoa (La comunidad perdida), en el espacio estructurante de la hacienda, que en Chile constituye un área privilegiada de reproducción cultural. Desde allí se fusionan, según este último autor, distintas tradiciones, las cuales dan origen a un amplio sistema de dominio que abarca desde la esfera sexual hasta la social, además de expresarse a nivel material y simbólico en la subordinación de aquellos considerados inferiores.

Por otra parte, para Fernández, con estas distintas clases de relaciones entre tropos, ya sean dinámicas o transformativas, se puede lograr una comprensión profunda de las interacciones sociales propias de una sociedad particular, ancladas en las formas de vida. Lo que en palabras de Rivera (Ch'ixinakax utxiwa: Una reflexión sobre prácticas y discursos descolonizadores) nos ayudaría a crear un perfil de quien dice algo, pues al nombrarlo, quedaría dicho lo dicho. Por tanto, hemos de asumir que una función muy peculiar de las palabras en el colonialismo es que estas no designan, sino por el contrario, encubren.

Veamos otro ejemplo en el siguiente juego de tropos: "Me voy a esclavizar seis meses más", "me he esforzado mucho para hacerme un nombre" (Contreras, Bambague y Barrera 2019:8). Ellos componen la dimensión configurativa de los relatos de mujeres migrantes en Chile que se desempeñan en labores de cuidado y del hogar. Estos tropos son perfectamente funcionales en relación con los procesos económicos globales, asociados a una serie de servicios especializados que las mujeres migrantes desarrollan en busca de sustento. A esto se suman los siguientes tropos mencionados por Contreras y Ramírez: "No estoy aquí para complacer a nadie", "uno cría a sus hijos para que no se sientan menos que nadie", "que aprenda que las cosas cuestan".

Estos tropos y los anteriores, figuran saberes que según autores como Olivos y Sandoval (Latina/o identities, the racialization of work, and the global reserve army of labor) y Padilla y Cuberos-Gallardo (Deconstruyendo al inmigrante latinoamericano) perpetúan dinámicas de poder alrededor de los puestos de trabajo en que se refuerzan las jerarquías coloniales. Lo que para Tijoux y Córdova (Racismo en Chile) reflejaría que la experiencia migratoria feminizada continúa funcionando en formas de explotación al interior de los países, dando cuenta de un horizonte colonial profundo que las atrapa entre normas y prácticas culturales diferentes. Todo esto en un contexto en que la migración en Chile, de acuerdo a datos del Censo 2017, suma 784.685 personas, lo que representa aproximadamente el $4,5 \%$ del total de población, en un territorio donde según Bidaseca et al. (La articulación entre raza, género y clase a partir de Aníbal Quijano) las marcas de la colonialidad se visibilizan en los lugares que las mujeres migrantes continúan ocupando, y en cuyo locus de enunciación se configura la maternidad. En este contexto, Contreras, Bambague y Barrera sostienen que la inevitable indigencia material de la existencia humana exigiría el esfuerzo y el trabajo a través de la disciplina corporal, lo que se materializa, en particular, en la práctica pedagógica que reproduce la distinción entre pobres merecedores y no merecedores.

5) Descubrir las grietas. Para ir más allá en el desvelo, es necesario descubrir si lo colonial deja alguna hendedura por donde pueda filtrarse lo decolonial. Para esto se requiere indagar en los relatos en que habitan los tropos, sus quiebres, microresistencias o fugas. Un ejemplo de ello se puede apreciar en el siguiente fragmento: "a lo mejor nosotros mismos le estamos enseñando a que nos miren en menos, cuando le decimos que sea más que uno" (Contreras 2013:302). 
Este relato da cuenta, en términos de relevancia, de cómo se estructura el saber en la vida cotidiana, según los intereses pragmáticos y la situación general, tornándose móvil e inconcluso, además de posibilitar fugas en la dinámica del juego de tropos. En otras palabras, se producen quiebres que en la medida que se entrecruzan, entregan una visión acerca de lo que podemos esperar de ellos. Así, al descubrir la importancia de las disposiciones básicas que conciernen a la vida cotidiana, es posible re-significar aquello que resulta relevante en ese giro. Sumado a esto, se releva la importancia de la experiencia en la adquisición de la "cuota de mercado" en el "consumo cultural" (Fernández 2006:14), lo que podría traer a colación los giros antes mencionados.

\section{A modo de cierre}

En síntesis, en los juegos de tropos y su articulación con el conjunto de reglas socio-históricas que regulan lo que puede y debe ser dicho, se produce una lectura y ordenamiento de lo que acontece a sujetos situados. Dicha acción es de tipo diverso y se despliega en las figuraciones del saber, permitiendo construirlo inductivamente, en y desde la tropología. Lo anterior nos lleva a plantear generalizaciones, como, por ejemplo, que al identificar los tropos-saberes a partir de investigaciones etnográficas específicas, particularmente desde relatos singulares, podemos llegar a determinar si estos habitan las matrices coloniales y en qué grado lo hacen. Específicamente, cuando los saberes están ligados íntimamente a la producción y reproducción de la vida y, por lo tanto, solo son funcionales al interior de una comunidad, perdiendo validez fuera del contexto concreto de sus mundos de vida.

Por otra parte, la tropología por su carácter posibilitador disminuye un aspecto álgido en el desafío del pensamiento decolonial, relacionado con las inevitables conformaciones de poder-saber, al introducir en el tropo la desviación respecto de la manera que se considera apropiada para designar un hecho, convirtiéndolo en un recurso que se mueve en lo no permitido.

Visto así y al igual que Boaventura de Sousa Santos (Epistemologías del sur), proponemos que en y desde la tropología se geste un espacio de solidaridad, posicionando a los otros en la categoría de alteridad radical. Desde esta perspectiva, el saber es reconocido como una instancia de elucidación, indagación y esclarecimiento de palabras borradas, conformando una teoría de la traducción que torna conmensurables los distintos saberes.

Asimismo, es importante señalar que en nuestra propuesta metodológica no abordamos el foco de los pronombres, como una opción orientada a relevar la contribución del tropo. Sin embargo, consideramos que esto es un asunto relevante e ineludible, por cuanto contribuye a la configuración del habitar-se. Específicamente, al anunciar la transformación-subyugación-subordinación del ser-saber, en y desde la función ideológica del tropo, ya que en la articulación de los pronombres y los tropos se responde a la función ideológica que pretende hacer sujetos de nosotros. Este principio releva, tal como lo hemos desarrollado en nuestra argumentación, que lo que realmente está en juego no son las condiciones reales de la existencia, sino la relación con esas condiciones, lo que se fundamenta en una interpretación, enunciando que no existen causas reales, sino que dichos vínculos se manifiestan de modo simbólico.

En el entendido que toda acción social se encuentra desde el comienzo simbólicamente determinada, es posible comprender que, en lugar de relacionarnos directamente con las condiciones de la existencia, éstas son representadas, por ejemplo, por los tropos u otros elementos, dejando su huella en el campo de las motivaciones, en nuestro sistema de imágenes o en el de representación del mundo. A esto se agrega, 
que los sentidos figurativos nos entregan información de tipo integradora, anunciando una función de la ideología que es imprescindible para todo grupo o sujeto, como es la de preservar la identidad.

Así, en nuestra propuesta, la mediación de lo simbólico no implica que el dominio del aspecto discursivo signifique que los cuerpos sean simples representaciones, por el contrario, en la figura de los tropos se releva que estos conforman una realidad concreta y material, en la que carne y huesos están sujetos también a una construcción discursiva social que se acata o subvierte.

Lo anterior comporta un aspecto performativo en que el sujeto al habitar-se descubre la orientación de su propio devenir de un modo no progresivo, que en algunos casos podría considerarse incluso regresivo. En otras palabras, la posibilidad de descubrir la orientación de forma parcial o incompleta es mediante la interpretación del síntoma y su transformación en discurso (tropo). Entonces, en el mismo momento en que se revela la radicalidad de la contingencia, se pone de manifiesto el poder en el que se ve envuelta la máxima posibilidad de elección y de manifestación de lo que hasta ese momento estuvo reprimido por la hegemonía. Visto así, podríamos decir que en los tropos converge la mayor imposibilidad con la mayor posibilidad del poder, dejando en evidencia que el sujeto en su habitar-se hace frente a la incompletud y a la imposibilidad de encontrar un significado que se adecúe al significante. No obstante, el impedimento de llegar a lo real maximiza su posibilidad de producir múltiples interpretaciones, entre las que deberá elegir una, produciendo efectos en la realidad.

Sin lugar a duda esta práctica sola no basta, se requiere de múltiples experiencias de liberación para que determinados sujetos y comunidades adopten formas válidas que transformen a los individuos en sujeto y cambien las relaciones de poder. Finalmente, hacemos hincapié en que la interpretación que realizamos de algunos juegos de tropos como figuraciones de saberes es solo una instantánea de un proceso imaginativo y complicado que, no obstante, expone la necesidad de rescatar los saberes de la vida cotidiana para convertirlos en fisura al momento de desvelar sus lastres coloniales. Esto se traduce en términos pedagógicos y éticos, en que el dar cuenta de la trama saber-tropo busca persuadir a quienes emprenden tareas investigativas a no desgastarse buscando procedimientos distantes y complejos, sino, por el contrario, considerar la narración como una práctica propia de la vida en común.

\section{Agradecimientos}

Artículo elaborado en el marco del proyecto Fondecyt 11150362. Se agradece el apoyo de la Dirección de Investigación Científica y Tecnológica (DICYT) de la Universidad de Santiago de Chile.

\section{Bibliografía}

Contreras, S. 2013. Esbozando una pedagogía vulnerable. Narrativas y retoricas locales. Tesis doctoral. Madrid: Universidad Complutense de Madrid.

Contreras, S; Bambague, C. y Barrera, Y. 2019. Saberes que configuran trayectorias migratorias: narraciones de mujeres colombianas migrantes en Chile. Convergencia Revista de Ciencias Sociales 79: 125. https://doi.org/10.29101/crcs.v0i79.9496

Fernández, J. 2006. La tropología y la figuración del pensamiento y de la acción social. Revista de antropología social 15: 7-20. 
Foucault, M. 2001. Defender la sociedad. Curso en el College de France (1975-1976). Buenos Aires: Fondo de Cultura Económica.

Gadamer, H. 2017. Arte y verdad de la palabra. Barcelona: Herder.

Haber, A. 2011. Nometodología payanesa: notas de metodología indisciplinada. Revista de Antropología 23: 9-49.

Ibáñez, J. 2014. Por una sociología de la vida cotidiana. Madrid: Siglo XXI.

Kusch, R. 1973. El pensamiento indígena y popular en América. Buenos Aires: ICA.

Perelman, C. y Olbrechts, L. 2009. Tratado de argumentación: La nueva retórica. Barcelona: Gredos.

Restrepo, G. 2007. Topos y tropos en la enseñanza ciudadana: una lectura excéntrica del lugar común de la pedagogía de los derechos humanos. REICE 5(4): 103-119.

Turner, T. 2008. Tropos, marcos de referencia y poderes. Revista de Antropología Social 15: 305-315.

Recibido el 12 Ago 2018

Aceptado el 26 Oct 2018 